\title{
Effect of stress triaxiality on fracture failure of 6061 aluminium alloy
}

\author{
L. Y. Kou ${ }^{1,2}$, W. Y. Zhao ${ }^{1}$, X. Y Tuo ${ }^{1}$, G. Wang ${ }^{1,2^{*}}$ and C. R. Sun ${ }^{3}$ \\ ${ }^{1}$ School of Mechanical Engineering, Ningxia University, 750021 Yinchuan, Ningxia, China \\ 2 The Key Laboratory of Ningxia Intelligent Equipment CAE, 750021 Yinchuan, Ningxia, China \\ ${ }^{3}$ State Key Laboratory of Advanced Design and Manufacturing for Vehicle Body, College of Mechanical and Vehicle Engineering, \\ Hunan University, 410082 Changsha, Hunan, China
}

ABSTRACT - The effect of stress triaxiality on mechanical properties of 6061 aluminium alloy extruded profiles with different specimens was studied. Macroscopic mechanical property of the various specimen was got through universal testing machine. At the same time, stress triaxiality of different specimens was obtained using the method of finite element simulation. And then the fracture strain of each specimen was outputted by DIC. Fracture modes of 6061 aluminium alloy with different stress triaxiality were studied by SEM. The results show that taking tensile samples as comparison, the cross-sectional area of some notched specimens decreases and the peak load increases. Among them, the minimum cross-sectional area of the R5 central hole specimen is $20 \%$ smaller than that of the tensile sample, and the peak load is $28 \%$ larger. The fracture strain of the alloy increased with the decrease of stress triaxiality. For the same notch specimens, along the path direction, stress triaxiality of R5 notch specimens, R5 Center-hole specimens and R20 Arc notched specimens increased $47 \%, 17.8 \%, 25 \%$ respectively. According to the analysis of fracture morphology, the main fracture of 6061 aluminium alloy was ductile fracture. When the stress triaxiality is large, the dimples are small and sparsely distributed, and when the stress triaxiality is small, the dimple is large and evenly distributed. Finally, the Johnson-Cook model material parameters of 6061 aluminum alloy are fitted based on the tensile test results of different shapes of specimens, which can accurately simulate the elastic-plastic deformation and fracture instability of 6061 aluminum alloy under different stress states.
ARTICLE HISTORY

Revised: $21^{\text {st }}$ April 2020

Accepted: $14^{\text {th }}$ May 2020

\section{KEYWORDS}

6061 aluminium alloy;

stress triaxiality;

digital image correlation;

fracture analysis;

Johnson-Cook failure

model.

\section{INTRODUCTION}

In recent years, in order to pursue the lightweight of car body, aluminum alloy has been widely used by major automobile enterprises because of its low density, high plasticity and high specific strength [1]. It also meets environmental requirements - reducing fuel consumption and carbon dioxide emissions. In the process of automobile collision, the stress state at each point of aluminium alloy component is different, which leads to the change of its failure behavior and failure time. Fracture failure is an important indicators and basis for the process production and safety evaluation of auto parts [2]. Therefore, it is very important to study the mechanical properties and damage forms of automotive aluminium alloy components under different stress states. Many researchers have analyzed the relationship between stress triaxiality and fracture strain. McClintock and Rice [3-4] studied the nucleation and polymerization growth process of different pore forms by using micropore body cell model, and explored the failure mechanism of micropore materials. The results showed that the fracture strain decreased with the increase of stress triaxiality. Gurson [5] established the Gurson model with parameters of stress triaxiality, plastic strain and micropore volume fraction to describe the plastic constitutive properties of materials. Lou [6] compared the experimental results of the fracture site constructed by the fracture criterion with that of AL2024-T351, and found that the modified Mohr-Coulomb criterion and the newly proposed criterion can effectively predict the fracture strain. Song [7] studied the mechanical response of Q345 steel strip specimen under uniaxial tensile action through experiments and finite element simulation. Non-notched specimens and notched specimens were used in this study. Through the fracture tests of aluminium alloy materials in different states, Tang [8] discussed the change rules of fracture forms of aluminium alloy materials under different stress triaxiality, including tensile fracture and shear fracture. Zhu [9-10] discussed the damage and fracture patterns of the notched aluminium alloy specimens under three stress states. Lu [11] obtained the micro-fracture mechanism of high-strength structural steel under different stress triaxiality states by analyzing the micro-morphology and structure changes of the fracture surface of high-strength structural steel samples. Wu [12] designed tensile, compression, torsion and fineblanking test for 45 steel, and analyzed the fracture mechanism under different stress states by combining the fracture morphology. Jia [13] proposed a more reasonable method for determining triaxial degree of stress of notched specimen combined with numerical simulation, which based on the distribution effect of strain path and triaxial degree of stress on the minimum cross section during the whole tensile process of notched specimen. Zhuang [14] compared the simulation results of Modified Mohr-Coulomb (MMC) fracture model, Cockcroft-Latham (CL) fracture model and MAT24 model 
in LS-DYNA through fracture tests under different stress states, and believed that the simulation results of MMC fracture criterion could more accurately describe the fracture characteristics of materials.

In the traditional experiments on the relationship between stress triaxiality and strain, the notch specimens with different radius are studied to achieve different stress triaxiality. Because the shape of the specimen is specific, the results are somewhat accidental. Moreover, the notched specimen has no parallel segment, which makes the calculation of output strain of the tensile machine more inaccurate. In this paper, plate specimens of different shapes are adopted. The stress triaxiality of different samples is obtained by finite element simulation. Digital image correlation (DIC) outputs relatively accurate fracture strain and analyzes the fracture micro-morphology of different specimens to study the mechanical properties and fracture mode of 6061 aluminium alloy with different stress triaxiality. The parameters of Johnson-Cook model were solved to provide the basis for the failure of aluminium alloy.

\section{EXPERIMENT}

The extrusion profile of 6061 aluminium alloy was selected in the experiment, and the element mass fraction was obtained by SEM element analysis, as shown in Table 1. DK77 wire cutting machine was used to intercept tensile specimens of different shapes in the above profiles along the extrusion direction of the profiles. The thickness was 2.8 $\mathrm{mm}$, and the size of the specimen was shown in Figure 1. All specimens were subjected to manual aging at $180{ }^{\circ} \mathrm{C}$ for 30 min. Tensile experiment was carried out on universal testing machine with displacement loading and loading rate of $1 \mathrm{~mm} / \mathrm{min}$. In order to study the deformation behavior of specimens of different shapes more accurately, DIC was used to conduct comparative analysis of tensile specimens of different shapes. This test used binocular camera test system. Before the test starts, speckle is made by standard speckle making tool, and the size of speckle is selected according to the specimen notch.

Table 1. Test 6061 aluminium alloy composition mass fraction (wt\%).

\begin{tabular}{llllllllll}
\hline Composition & $\mathrm{Cu}$ & $\mathrm{Mn}$ & $\mathrm{Mg}$ & $\mathrm{Zn}$ & $\mathrm{Cr}$ & $\mathrm{Ti}$ & $\mathrm{Si}$ & $\mathrm{Fe}$ & $\mathrm{Al}$ \\
\hline \multirow{2}{*}{ Content } & 0.13 & $\begin{array}{c}< \\
0.01\end{array}$ & 0.74 & 0.01 & 0.02 & $\begin{array}{l}< \\
0.01\end{array}$ & \multirow{2}{*}{0.56} & 0.03 & Rest \\
\hline
\end{tabular}

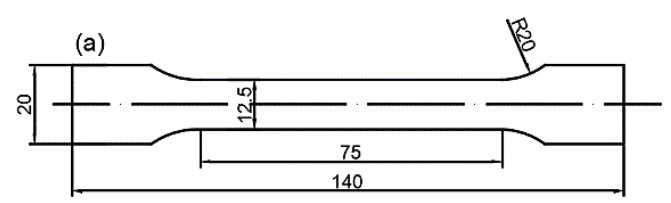

(c)
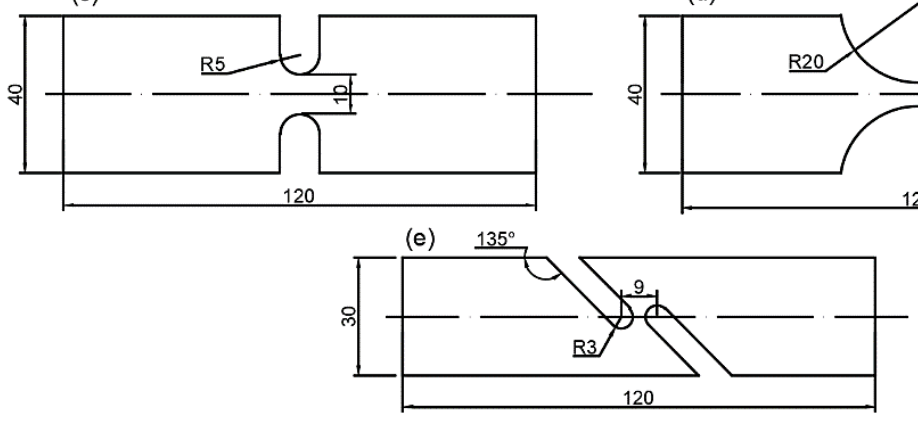

(b)

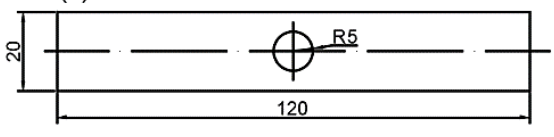

(d)

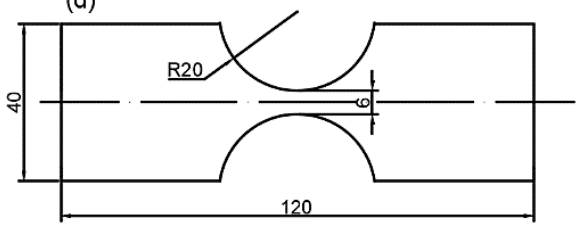

120

Figure 1. Specimen size diagram in millimeters: (a) tensile specimen, (b) R5 central hole specimen, (c) R5 notched specimen, (d) R20 arc notched specimen and (e) shear specimen.

\section{RESULTS AND ANALYSIS}

\section{Analysis of Experiment and Simulation Results}

The true stress-strain of the tensile specimen were obtained by modifying the displacement by DIC virtual extensometer and the force by the tensile machine. According to the true stress-strain curve, the yield stress of the material $\mathrm{A}=175 \mathrm{MPa}$, the strain hardening modulus $\mathrm{B}=415.3 \mathrm{MPa}$, and the hardening index $\mathrm{n}=0.546$. Table 2 shows the peak load and displacement of specimens with different shapes. It can be found that the minimum peak load of shear specimens is $1.221 \mathrm{kN}$. This is because shear specimen has the smallest cross-sectional area, the bearing capacity is small. However, the minimum cross-sectional area of the R5 notch specimen is $20 \%$ smaller than the tensile sample, and the peak load is 
$19.3 \%$ larger. The cross-sectional area of the R5 central hole specimen is $20 \%$ smaller than that of the tensile sample, and the peak load is $28 \%$ larger. This is the result of notch strengthening. The largest peak load belongs to R5 notch specimen, $10.681 \mathrm{kN}$.

Table 2. Peak load and displacement of specimens at fracture.

\begin{tabular}{ccc}
\hline Name & Peak load/kN & Displacement $/ \mathrm{mm}$ \\
\hline Shear specimen & 1.221 & 4.012 \\
Tensile specimen & 8.339 & 11.081 \\
R20 Arc notched specimen & 6.056 & 1.803 \\
R5 Central hole specimen & 9.950 & 2.163 \\
R5 Notched specimen & 10.681 & 1.910 \\
\hline
\end{tabular}

In this paper, the fully integrated shell element is used by LS-DYNA during the simulation. The quadrilateral grid with the minimum element size of $0.2 \mathrm{~mm}$ is adopted. The full projection warping stiffness for accurate solutions with type 16 fully integrated shell elements is actived with a coefficient of 0.1 . It was obtained the relationship between the stress triaxiality and the equivalent plastic strain at the fracture of specimen with different shapes and the stress triaxiality on the path of the minimum cross section of specimens with different shapes. The "path" refers to the minimum section of the specimens. The upper notch root and the lower notch root of the specimens are the starting and ending points of the path respectively. The length of path is the minimum width of the specimens. And the path of R5 circular hole specimen consists of two sections.

Figure 2 shows that the stress triaxiality of the shear specimen is the minimum, which benefits from the good plastic deformation capacity. The stress triaxiality of tensile specimen hardly fluctuates in the process of tensile, remaining at about 0.33 . The maximum stress triaxiality of R5 notch specimen reaches about 0.5 . The fracture strain increases with the decrease of stress triaxiality. The stress triaxiality reflects the degree of restraint on the plastic deformation capacity of the material, so with the increasing of stress triaxiality increases, the plastic deformation capacity of the material would decrease. At the same condition, the failure strain of high stress triaxiality material would be low [15].

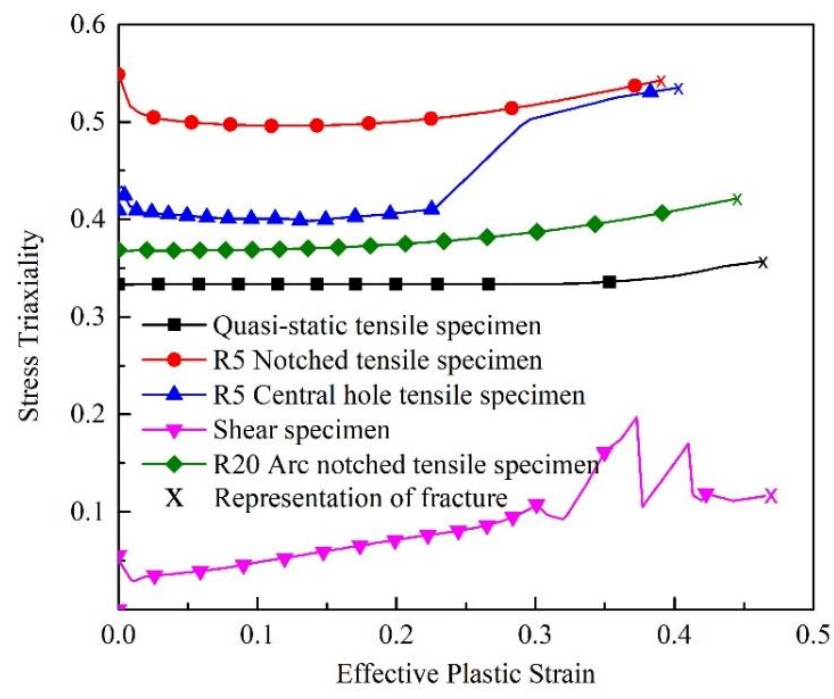

Figure 2. Tress triaxiality and strain of the specimens.

Figure 3 shows that the stress triaxiality of the tensile specimens with different shapes on the minimum cross section are obviously different. Figure 3(a) shows that the stress triaxiality of the tensile specimens does not change with the path and remains at about 0.33 . The stress triaxiality distribution curve of shear specimens is shown in Figure 3(b). It is obvious that the specimen is subjected to tensile shear force instead of pure shear force. The stress triaxiality reached a maximum value of 0.33 at the root of the notch, and about 0.1 at the middle path. Figure 3(c) shows the stress triaxiality of R5 notched specimens, the minimum value is 0.34 . The stress triaxiality increases firstly and then decreases along the path, the maximum value is 0.5 at the center of the specimen. Figure 3(d) shows that the stress triaxiality increases to 0.41 with the path firstly, because of the upper and the lower sections of the specimen with R5 central hole. Then it decreases to 0.348 at the circumference of the center hole, and return to 0.41 from the lower circumference. Finally, it drops to 0.341 at the edge of the specimen. Figure 3(e) shows that the stress triaxiality of R20 notched specimen is 0.336 at the notch root, which rises to the maximum value of 0.42 at about $2.63 \mathrm{~mm}$ away from the notch root, and it decreases to 0.4 at about $2.84 \mathrm{~mm}$ away from the notch root. From the above contents, it can be known that the stress triaxiality of notch 
specimen in this paper has a minimum value at the beginning and end of the path. For the same notch specimens, along the path direction, stress triaxiality of R5 notch specimens, R5 Center-hole specimens and R20 Arc notched specimens increased 47\%, 17.8\%, 25\% respectively. The stress triaxiality of Figure 3(a), (c), (d), (e) is symmetrical along the path direction, and the tensile specimen, R5 notched specimen, R5 center hole specimen and R20 arc notched specimen are all axisymmetric figures. This shows that the stress triaxiality of the minimum cross-section is symmetrical when uniform axisymmetric plate specimen is under static tension.
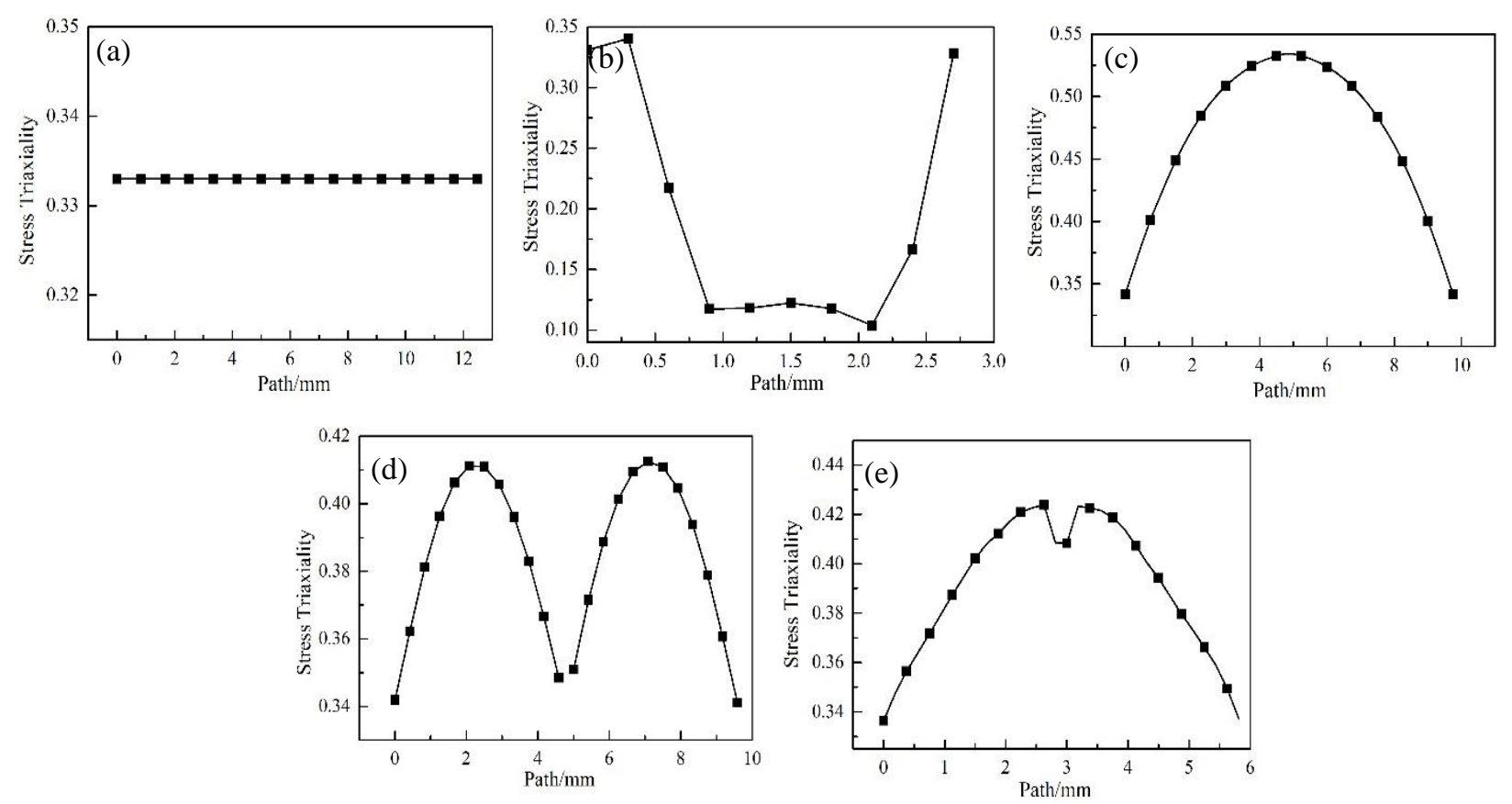

Figure 3. Stress triaxiality of different specimens varies with path: (a) tensile specimen, (b) shear specimen pecimens, (c) R5 notch specimen, (d) R5 center-hole specimens and (e) R20 arc notched specimen.

\section{DIC Result Analysis}

As shown in Table 3, maximum normal strain and maximum shear strain at the moment before fracture can be obtained by DIC stress field analyzed. It can be seen that, except for the shear specimen, the maximum normal strain and shear strain decrease in turn, and the trend of strain variation is the same as that obtained by numerical simulation.

Table 3. Maximum normal strain and shear strain of specimen.

\begin{tabular}{lll}
\hline Name & Maximum normal strain & Maximum shear strain \\
\hline Shear specimen & 1.060 & 0.677 \\
Tensile specimens & 0.280 & 0.162 \\
R20 Arc notched specimen & 0.258 & 0.141 \\
R5 Central hole specimen & 0.226 & 0.139 \\
R5 Notched specimen & 0.189 & 0.103 \\
\hline
\end{tabular}

Figure 4 and Figure 5 are normal strain and shear strain nephograms of specimens with different shapes at the moment before fracture. The specimens in each group of pictures are arranged from left to right in the order of tensile specimen, R20 arc notch specimen, R5 circular notch specimen, and R5 notch specimen. It can be seen that the maximum values of normal strain and shear strain are at the notch root, where the stress triaxiality of each specimen is the smallest. 


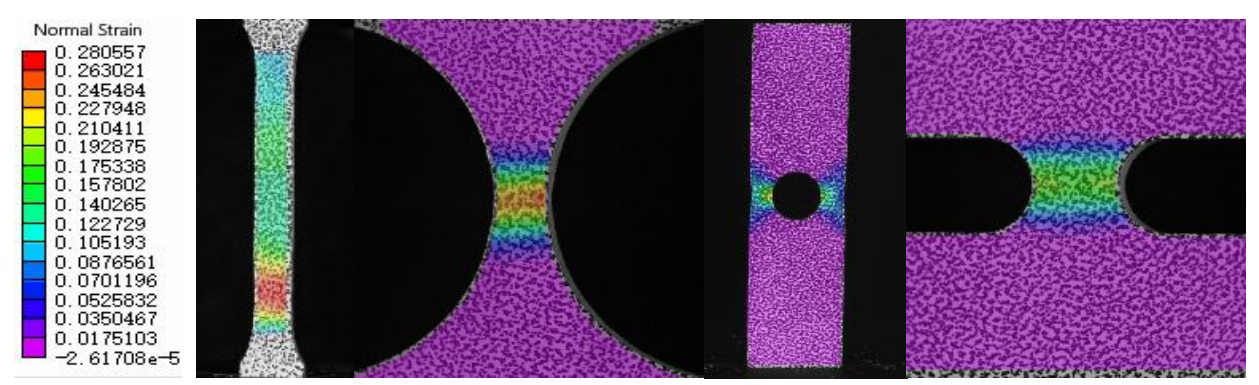

Figure 4. Normal strain nephogram of the specimens.

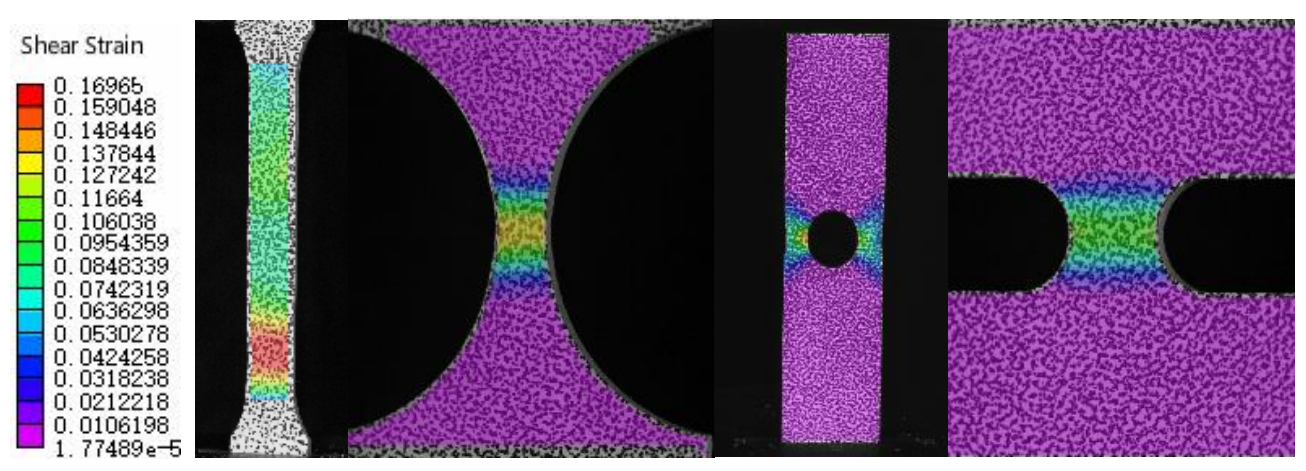

Figure 5. Shear strain nephogram of the specimens.

\section{SEM Morphology Analysis of Fracture}

As shown in Figure 6, a large area of shear zone appears on the fracture of the shear specimen, indicating that the direction of the fracture surface is consistent with the direction of the maximum shear stress. At the same time, there are a few micro-holes in the fracture surface. However, due to the low stress triaxiality, the plastic deformation, in the fracture process, is quite large, and the plastic slip will produce a large number of shear zone. The holes are not easy to expand. Finally, under the action of shear stress, the micro-holes are gradually covered by shear zone, and the fracture is a typical shear slip fracture.

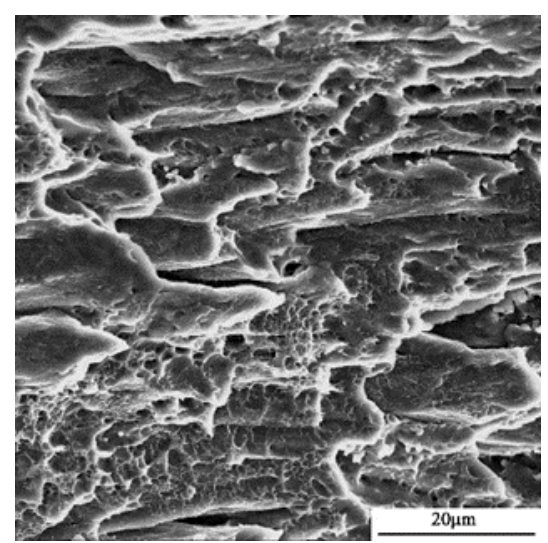

Figure 6. Fracture of shear specimen.

The fracture morphology of R5 center hole specimen is shown in Figure 7. There are obvious differences between the two. Figure 7(a) shows that there are obvious elliptical dimples and a few shear zones, indicating that there are mixed normal and shear faults in the center of the fracture. Figure 7(b) shows micropores and tearing edges, indicating that the fracture edge is quasi-cleavage fracture. According to Figure 3(d), this is because the stress triaxiality at the center of the fracture is larger than that at the edge of the fracture. The fracture strain at the center is small and breaks in advance. With the increase of load, the stress concentration at the edge of the port increases and quasi-cleavage fracture occurs [16]. 

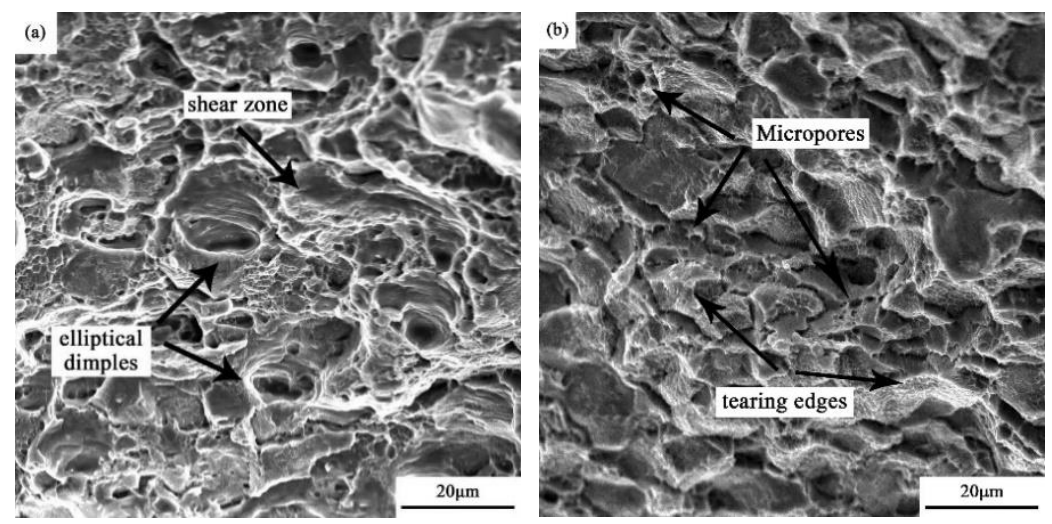

Figure 7. Fracture of R5 center hole specimen; (a) the center, (b) near the outer edge.

As shown in Figure 8(a), deep and uniform circular dimples are found on the fracture surface of the tensile specimen. Second-phase particles can be seen in the dimples. Holes nucleate, grow and aggregate at the second-phase particles, which eventually lead to fracture. The fracture mode is typical of normal void fracture [17]. A small number of large dimples can be seen in Figure 8(b), but the size is smaller than that in Figure 8(a). At the same time, smaller dimples are distributed around the dimples, forming honeycomb-like ductile zone, which are in the mode of fracture between the normal fracture of the hole and the shear fracture of the hole. The fracture micromorphology in Figure 8(c) is similar to that in Figure 8(b), but the size of dimples is smaller, with a little number of large dimples. This is because the stress triaxiality of the tensile specimen is smaller. The plastic deformation is larger during fracture and the fracture strain is larger. The holes gradually form larger dimples. However, the stress triaxiality of R5 notch specimen and R20 arc notch specimen is relatively large, and the plastic deformation capacity is poor. The fracture occurs before the hole grows into a large dimple.
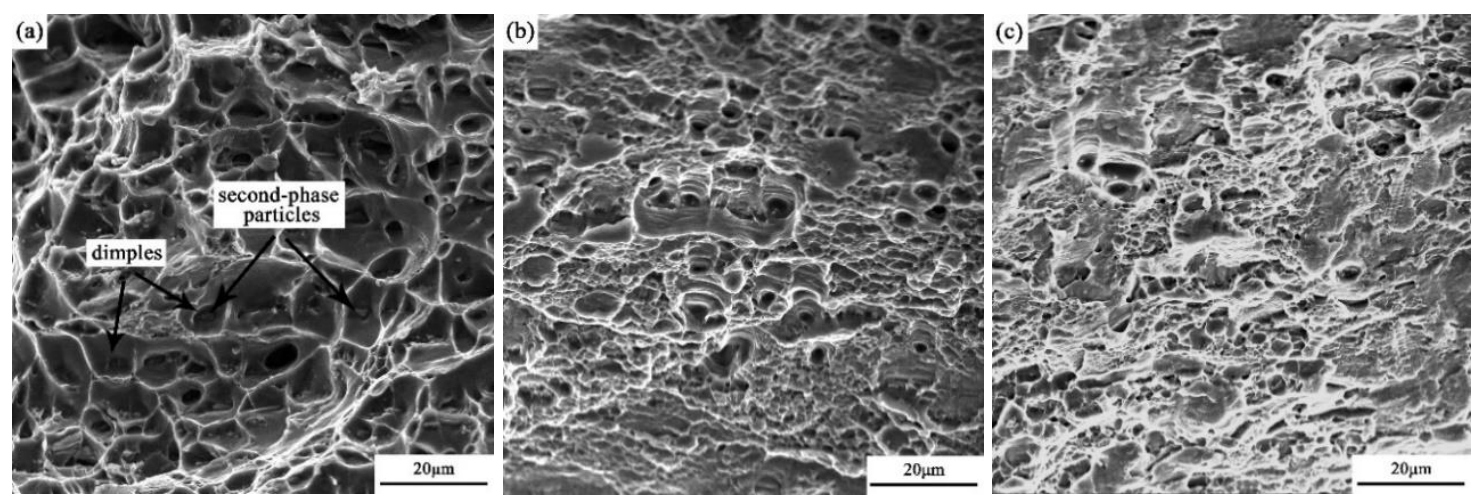

Figure 8. Fracture SEM morphology of three specimens; (a) tensile specimens, (b) R20 arc notched specimens,

(c) R5 notched specimens.

\section{SIMULATION MODEL SELECTION AND PARAMETER CALCULATION}

\section{Elastoplastic Mechanical Parameters}

In order to study the mechanical properties and deformation behavior of 6061 aluminum alloy plate during the whole process of elastic-plastic deformation to fracture under different stress states, the non-contact full-field strain measurement system was used to collect the digital images of various deformation stages of the object in real time [18]. In this paper, the true stress and true strain of the quasi-static tensile specimen are calculated by using the total displacement output by the DIC virtual extensometer and the force output by the tensile machine as shown in Figure 9. The formula of true strain and true stress are as following [19]:

$$
\begin{gathered}
\varepsilon_{t}=\ln \left(l_{f} / l_{0}\right) \\
\sigma_{t}=\mathrm{P} / A_{i}
\end{gathered}
$$

where $l_{f}$ is final standard distance length; $l_{0}$ is initial standard distance length; $\mathrm{P}$ is load; $A_{i}$ is cross sectional area. 


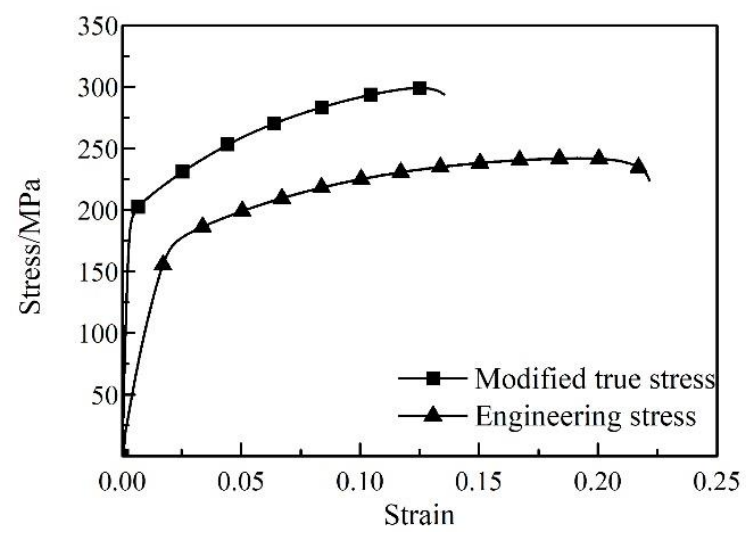

Figure 9. True stress and engineering stress diagram of quasi-static specimen.

The modified constitutive equation is used in the plasticity stage:

$$
\sigma_{t}=\left(\mathrm{A}+\mathrm{B} \bar{\varepsilon}^{p^{n}}\right)\left(1+\mathrm{cln} \varepsilon^{*}\right)\left(1-T^{*}\right)
$$

where A, B, n, c are material parameters. A is yield limit of material; $\varepsilon^{*}$ is the normalized damage equivalent plastic strain rate; $T^{*}$ is the homologous temperature. The samples in this paper are all tensile at room temperature, and the strain rate does not exceed $10^{3} \mathrm{~s}^{-1}$. Therefore, the influences of strain rate and temperature are ignored. The equation can be obtained:

$$
\sigma_{t}=\mathrm{A}+\mathrm{B} \bar{\varepsilon}^{p^{n}}
$$

The material parameters are obtained by fitting calculation: $A=175 \mathrm{MPa} ; B=415.2 \mathrm{MPa} ; n=0.546$. The fitting results and experimental data are shown in the Figure 10.

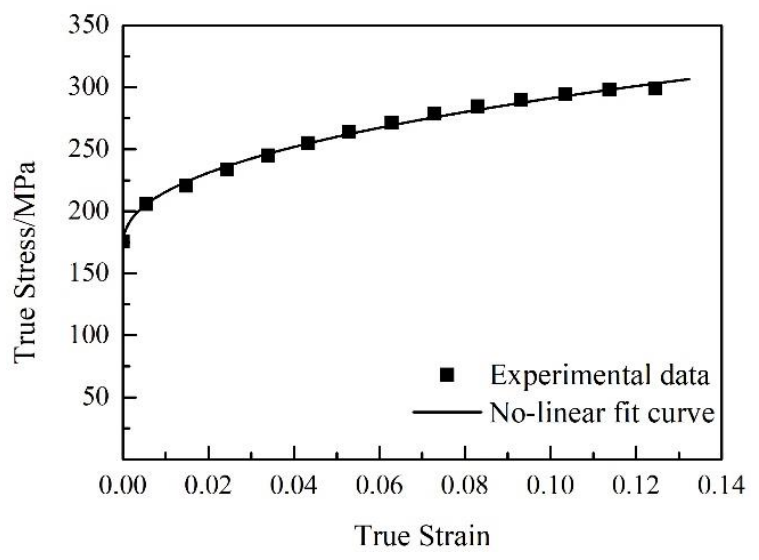

Figure 10. Material parameter fitting and test true stress true strain curve.

\section{Ductile Fracture Mechanical Parameters}

MAT24 means a PIECEWISE LINEAR PLASTICITY constitutive model in LS-DYNA program, and it was used to calculate the stress triaxiality in the first stage. The simulation material model is only given stress and strain parameters, fracture criteria and related parameters are not set. Therefore, the simulation curve will keep increasing in the plastic section.

MAT107 means a MODIFIED JOHNSON COOK constitutive model in LS-DYNA programand it was selected because the effects of stress triaxial, strain rate and temperature are considered in Johnson-Cook damage evolution rule. It is important to determine the "starting point of fracture". Since the fracture of ductile materials is the result of the development and accumulation of the damage caused by plastic deformation, the initial point of the damage is the nucleation of holes. Fracture caused by hole connection is the peak point of damage accumulation. Yang [20] studied the forming limit of 5182 aluminum plate based on Lou-2013 ductile fracture criterion, the bifurcating point of the test and simulation force curve was taken as the macroscopic embodiment of the initial damage. Li [21] defined the initial time 
of fracture as the time when the steep drop point appeared on the load-displacement curve in the analysis of fracture prediction of high strength steel materials and steel structures based on micro-mechanism fracture theory. Zhu [22] took the maximum equivalent strain point corresponding to the fracture displacement moment in physical experiment as the starting point of fracture in the study of the influence of strain path change on ductile fracture of materials. In this paper, the maximum Von Mises strain value at the time of fracture read by DIC is taken as the "starting point of fracture". Most researchers take the starting point of the fracture at the center of the minimum section [23]. The samples are all fractured at the minimum cross sectional area and the minimum interface center is also the maximum stress triaxiality. In order to consider the influence of overall stress triaxiality on fracture before initiation, the stress triaxiality average of historical variation was calculated from the beginning of plastic deformation to the beginning of fracture. The following integral formula is used for calculation [24]:

$$
\sigma_{a v g}^{*}=\frac{1}{\bar{\varepsilon}_{f}^{p}} \int_{0}^{\bar{\varepsilon}_{f}^{p}} \sigma^{*}\left(\bar{\varepsilon}^{p}\right) d \bar{\varepsilon}^{p}
$$

where $\bar{\varepsilon}_{f}^{p}$ is equivalent plastic fracture strain; $\bar{\varepsilon}^{p}$ equivalent plastic strain. The stress triaxiality is defined:

$$
\sigma^{*}=\sigma_{H} / \sigma_{e q}
$$

where $\sigma_{H}$ is average stress; $\sigma_{e q}$ is equivalent stress. The extended Johnson-Cook damage evolution rule:

$$
\mathrm{D}=\sum \frac{\Delta \varepsilon^{p}}{\varepsilon_{f}}
$$

where $\mathrm{D}$ is damage parameter $(0 \leq \mathrm{D} \leq 1)$. When the material is not deformed, $\mathrm{D}=0$. As the damage accumulates, the plastic strain increases, and when $\mathrm{D}$ is equal to 1 , the material fails. $\Delta \varepsilon^{p}$ is plastic strain increment. Where the current equivalent fracture strain $\varepsilon_{f}$ is defined by

$$
\varepsilon_{f}=\left(D_{1}+D_{2} e^{D_{3} \sigma^{*}}\right)\left(1+D_{4} \ln \varepsilon^{*}\right)\left(1+D_{5} \mathrm{~T}^{*}\right)
$$

where $D_{1}, D_{2}, D_{3}, D_{4}, D_{5}$ are material parameters. The influences of strain rate and temperature were ignored, the equation was obtained:

$$
\varepsilon_{f}=\left(D_{1}+D_{2} \mathrm{e}^{D_{3} \sigma^{*}}\right)
$$

According to the relation of equivalent fracture strain and stress triaxiality, nonlinear fitting is shown in the Figure 11. Material parameters: $D_{1}=0.248 ; D_{2}=11.86 ; D_{3}=-13.15$. According to the linear regression correlation, the linear regression coefficient is greater than 0.99. It shows that the experimental data and the fitting results are extremely consistent.

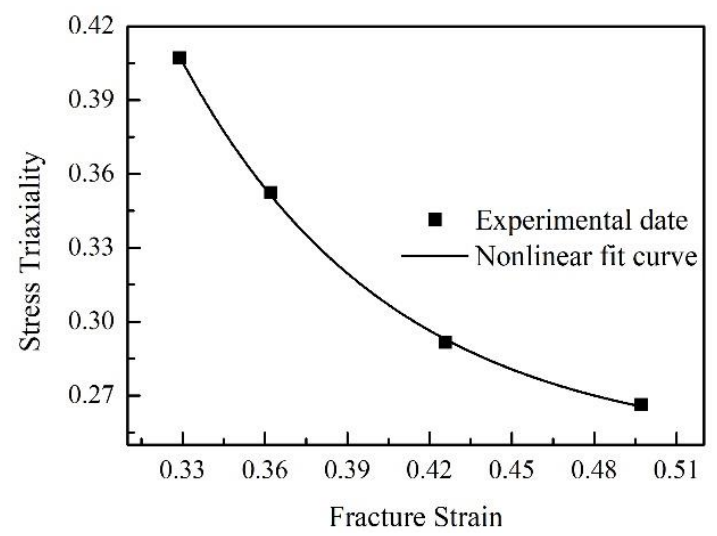

Figure 11. Relationship of stress triaxiality and fracture strain.

The simulation curve is obtained by substituting material parameters into MAT107 as shown in Figure 12. The curve (a) (b) (c) (d) shows that the error between the simulated displacement at the time of fracture and the test is as follows: $6.5 \%, 4.2 \%, 7.3 \%, 0.9 \%$. This indicates that the numerical simulation has high precision. The results show that the material parameters obtained are reasonable. 


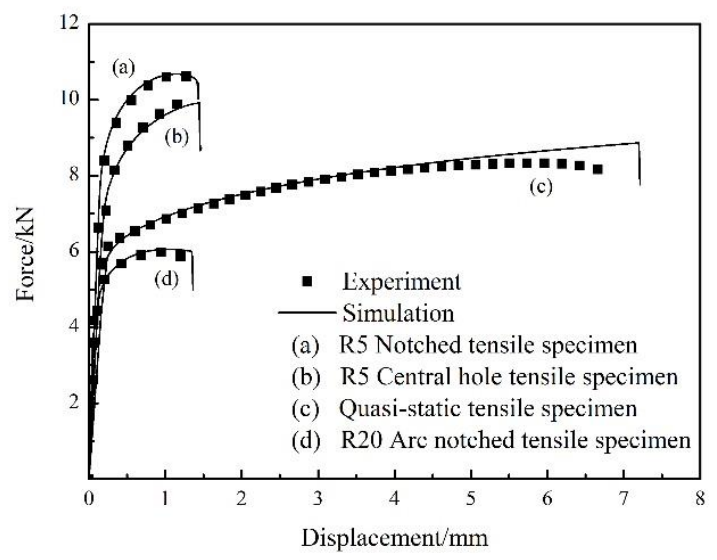

Figure 12. Experimental and simulated force and displacement curves.

\section{CONCLUSIONS}

The tensile test and simulation of 6061 aluminum alloy samples with different shapes were successfully conducted. The results are summarized below:

1) Due to notch strengthening, the peak load of R5 notch specimens and R5 center-hole specimens is higher than that of tensile specimens $19.3 \%, 28 \%$ respectively.

2) Under the condition of low stress triaxiality, the stress triaxiality increases with the decrease of fracture strain. The stress triaxiality of shear specimens, tensile specimens, R20 arc notch specimens, R5 central hole specimens and R5 notch specimens increased from 0.1 to 0.5 , and the fracture strain decreased from 1.06 to 0.189 .

3) Ductile fracture occurred in 6061 aluminum alloy. The fracture modes are different with the change of the stress triaxiality. The dimple morphology of the fracture section of the same specimen also changes with variety of the triaxiality of the section.

4) Based on the Johnson-Cook fracture criterion, the elastic-plastic deformation and fracture instability of 6061 aluminium alloy under different stress states can be accurately simulated by calculating the material parameters of 6061 aluminium alloy.

\section{ACKNOWLEDGMENTS}

The authors gratefully acknowledge research support from the Ningxia Natural Science Foundation of China (2018AAC03061), the National Natural Science Foundation of China (51605234), the Ningxia Key Research and Development Project of China (2017, Western Light), the Major Innovation Projects for Building First-Class Universities in China's Western Region (ZKZD2017010) and Ningxia Autonomous Region Science and Technology Research (Support) Project (Key Technologies of High-end Valve Structural Optimization and Erosion Performance Research).

\section{REFERENCES}

[1] N. Le Maoût, S. Thuillier and P. Y. "Manach, Aluminum alloy damage evolution for different strain paths - Application to hemming process," Eng. Fract. Mech., vol. 76, no. 9, pp. 1202-1214, 2009, doi: 10.1016/j.engfracmech.2009.01.018.

[2] F. A. Mcclintock, "A criterion for ductile fracture by the growth of holes," J. Appl. Mech., vol. 35, no. 2, pp. 363-371, 1968, doi: $10.1115 / 1.3601204$.

[3] J. R. Rice and D. M. "Racey, On the ductile enlargement of voids in trixial stress fields," J. Mech. Phys. Solids., vol. 17, no. 3, pp. 201-217, 1969, doi: 10.1016/0022-5096(69)90033-7.

[4] A. L. Gurson, "Continuum theory of ductile rupture by void nucleation and growth," J. Eng. Mater. Technol., vol. 99, pp. 215, 1977, doi: 10.1115/1.3443401

[5] Y. S. Lou and H. Huh, "Evaluation of ductile criteria in a general three-dimensional stress state considering the stress triaxiality and the lode parameter," Acta Mech. Solida Sin., vol. 26, no. 6, pp. 642-658, 2013, doi: 10.1016/S0894-9166(14)60008-2.

[6] Q. Song, Y. Huang and J. Zhang, "Simulation on tensile behavior of Q345 steel notched plate and revision of constitutive relation,” J. Guangxi Univ., vol. 4, pp. 1554-1561, 2018, doi: 10.13624/j.cnki.issn.1001-7445.2018.1554.

[7] A. M. Tang and Z. M. Liu, "The Experiment Analysis for Fracture Laws of Aluminum Alloy Materials," J. Xi'an Univ. Tech., 2003, vol. 3226-229.

[8] H. Zhu, L. Zhu and J. H. Chen, "Study of mechanical performance and analysis of fracture surfaces of aluminum alloy in three patterns of stress state," J. Lanzhou Univ. Tech., vol. 32, no. 6, pp. 28-31, 2006, doi: 10.1016/S1003-6326(06)60040-X. 
[9] H. Zhu, L. Zhu and J. H. Chen. "Fracture Mechanism on 6063 Aluminum Alloy under Different Stress States by in-Situ Tensile,” Rare Met. Mater. Eng., vol. 7, pp. 1183-1187, 2008, doi: 10.1016/j.precisioneng.2007.08.007.

[10] M. Lu, J. Yang and F. F. Liao, "Fracture mechanism of Q460D structural steel under different stress state," Heat Treat. Met., vol. 41, no. 7, pp.172-177, 2016, doi: 10.13251/j.issn.0254-6051.2016.07.041.

[11] Y. J. Wu, X. C. Zhuang and Z. Zhao, "Fracture topography analysis of C45 steel under different stress state," J. Plast. Eng., vol. 20, no. 3, pp. 106-110, 2013, doi: 10.3969/j.issn.1007-2012.2013.03.020

[12] X. L. Jia, J. Wang and Y. L. Zhang, "Mechanical behavior of typical materials under full load under complex stress," Chin. J. Appl. Fundam. Eng. Sci., vol. 2, pp. 202-213, 2017, doi: CNKI: SUN: YJGX.0.2017-02-018

[13] D. Jia, X. C. Huang and J. Mo. "A method to determine stress triaxiality of notched specimens from tensile tests," in China Conference on Computational Mechanics, 2012.

[14] H. Y. Zhuang, Y. M. Tian and X. H. Lai. "Fracture test and fracture model establishment of sheet metal under different stress states," Automob. Tech. Mater., 2016; 11: 43-47. 10.3969/j.issn.1003-8817.2016.11.014

[15] S. J. Fan, G. Q, He and X. S. Liu, "Analysis of The Microstructure and Tensile Fractographs of A356 Alloy," Met. Funct. Mater., vol. 14, no. 2, pp. 24-27, 2007.

[16] X. M. Zhang, L. H. Hao and D. M. Jiang, “An Investigation on Tenile Fracture of Al-Mg-Si Alloys,” J. Mater. Eng., vol. 5, pp. 35-36, 1996.

[17] Z. X. Zhou, Y. L. Li and T. Suo. "Microstructure and Dynami Mechanical Properties of 2A14 Aluminium Alloy Sheet," Mech. Sci. Tech. Aerosp. Eng., vol. 28, no. 11, pp. 1464-1467, 2009, doi: 10.1061/41039(345)45.

[18] L. Wang. Experimental Studies about Dynamic Responses and Fracture Criteria of Q460GJ Structural Steel Considering Stress Triaxiality and Strain-Rate Effects. Chongqing, CHN: Chongqing Univ, 2012.

[19] Y. L. Li. "Definition and Mechanical Characteristics of True Stress-Strain," J. Chongqing. Univ., vol. 24, no. 3, pp. 58-60, 2001.

[20] Z. Y. Yang, C. C. Zhao, G. J. Dong, "Forming limit research of 5182 aluminum alloy sheet based on Lou-2013 ductile fracture criterion,” J. Mech. ENG., vol. 55, no. 16, pp. 47-57, 2019, doi: 10.13330/j.issn.1000-3940.2017.03.028.

[21] W. C. Li. Research on application of micro-mechanism based fracture theory in fracture prediction analysis of high-strength steel and structures. Xi'an, CHN: Chang'an Univ, 2017.

[22] X. F. Zhu, T. T. Wang, X. C. Zhuang, et al, "Effect of strain path change on ductile fracture of materials," Forg. Technol., vol. 41, no. 6, pp.122-127, 2016, doi: 10.13330/j.issn.1000-3940.2016.06.023.

[23] H. Kudo, K, Aoi, "Effect of compression test conditions upon fracturing of medium carbon steel," J. Jap. Soc. Techno. Plastic., vol. 18, pp.17-27, 1967.

[24] F. X. Jin, Z. P. Zhong, F. J. Li, "Influence of Different Hardening Model for the Simulating Results of the Aluminum Alloy Sheet Stamping," J. Mech. ENG., vol. 53, no. 22, pp.57-66, 2017, doi: 10.3901/JME.2017.22.057. 